\title{
MOBILIDADE ESPACIAL DOS IMIGRANTES ESTRANGEIROS NO BRASIL - 1991/2010
}

\author{
Weber Soares ${ }^{1}$ \\ Carlos Lobo ${ }^{2}$ \\ Ralfo Matos $^{3}$
}

\begin{abstract}
Na formação do território brasileiro, os fluxos migratórios internacionais e internos desempenharam papel central. Se as correntes de imigrantes oriundas da África e da Europa fomentaram as atividades econômicas do passado, as novas ondas migratórias, a contar de meados do século XX, conformaram a dinâmica socioespacial brasileira mais recente. Ao lado de tradicionais destinos como o Japão e Estados Unidos, novos movimentos populacionais internos à América do Sul ganharam importância, incluindo os fluxos de entrada no território brasileiro. Em face dessa dinâmica migratória, constitui objetivo principal deste trabalho o levantamento das diferentes nacionalidades dos imigrantes estrangeiros residentes no Brasil e a análise das diferenças na mobilidade espacial interna desses mesmos estrangeiros. De acordo com dados extraídos dos censos demográficos de 1991, 2000 e 2010, nota-se uma expressiva expansão do número de estrangeiros naturais dos países latino-americanos em terras brasileiras, em especial dos vizinhos do cone sul, e um significativo nível de mobilidade espacial interna dos paraguaios e dos bolivianos.
\end{abstract}

Palavras-chave: mobilidade espacial, migração interna, migração internacional.

\section{Introdução}

A economia brasileira encontrou, no terceiro quartel do século XIX, um produto que permitiu reintegrá-la às correntes em expansão do comércio internacional, o café; restava resolver, no entanto, o problema da mão de obra.

1 Departamento de Geografia da Universidade Federal de Minas Gerais, Belo Horizonte, MG, Brasil.

2 Departamento de Geografia da Universidade Federal de Minas Gerais, Belo Horizonte, MG, Brasil.

3 Departamento de Geografia do Instituto de Geociências da Universidade Federal de Minas Gerais, Belo Horizonte, MG, Brasil. 
Solução que passou pelo fomento estatal à imigração europeia. Se no Brasil o problema era o de escassez de mão de obra, na Europa, ao longo do século XIX, verificou-se um crescimento demográfico sem precedentes que, aliado aos avanços tecnológicos no âmbito da produção e da melhoria dos meios de transporte, punha à disposição do mercado grande excedente de força de trabalho. Foi em virtude das tendências populacionais inscritas nesse quadro sociodemográfico europeu que, no período 1870/1930, a chamada "grande imigração" fundamentou a transição do trabalho escravo para o trabalho livre no Brasil.

Nos anos 70 do século XIX, a imigração internacional ganhou força: ao passo que entre 1820 e 1876 pouco mais de 350 mil estrangeiros entraram no Brasil, no período 1872/1930, o número de imigrantes internacionais foi da ordem de 4,1 milhões ${ }^{4}$. A distribuição desse total segundo a nacionalidade, a saber, 1.195.052 portugueses, 1.479.363 italianos, 574.565 espanhóis, 86.577 japoneses, 165.861 alemães e 606.385 outros põe em evidência Portugal e Itália como principais países de origem desses fluxos populacionais ${ }^{5}$. Além disso, pelo que se infere pelos dados dos censos demográficos concentraram-se nas regiões Sul e Sudeste: em 1872, 84\% imigrantes estrangeiros residiam nessas duas regiões e, em 1900, esse percentual chegou à casa de $97 \%{ }^{6}$. Eliminada na segunda metade do século XIX a única fonte importante de imigração, que era a escrava, a questão da mão de obra agrava-se e passa a exigir urgente solução. Em face desse problema, são lançadas as bases para a formação da grande corrente imigratória que tornaria possível a expansão da produção cafeeira no estado de São Paulo. O número de imigrantes europeus que entra nesse estado sobe de 13 mil, nos anos setenta, para 184 mil no decênio seguinte e 609 mil no último decênio do século. O total para o último quartel do século foi de $803 \mathrm{mil}^{7}$.

A década de 1930 constitui referência temporal da drástica redução da imigração estrangeira e de início dos intensos movimentos migratórios internos que caracterizarão, daí em diante, a dinâmica populacional brasileira. A transferência do eixo de acumulação do setor primário para o urbano industrial instaura dois tipos de movimentos migratórios simultâneos e aparentemente contraditórios $^{8}$, a saber: interiorização - a ocupação de novas fronteiras agrícolas -, e urbanização, que responderam pela mudança no perfil da distribuição territorial da população no País.

4 BAENINGER, Rosana. Fases e faces da migração em São Paulo.

5 Ibidem.

6 SALES, Teresa; BAENINGER, Rosana. Migrações internas e internacionais no Brasil: panorama deste século.

7 FURTADO, Celso. Formação econômica do Brasil.

8 MARTINE, George. A evolução espacial da população brasileira; IDEM. As migrações de origem rural no Brasil: uma perspectiva histórica. IDEM. Estado, economia e mobilidade geográfica: retrospectiva e perspectivas para o fim do século. 
O intenso crescimento da economia com sua grande capacidade de geração de empregos, as altas taxas de crescimento demográfico e a reorganização socioeconômica do território brasileiro ensejaram o perfil migratório que prevaleceu de 1940 até 1980 . Suas características essenciais adquirem a seguinte discriminação: 1) trajetórias dominantes que tinham como origem dois grandes reservatórios de forca de trabalho - Minas e Nordeste - e como destino as regiões de expansão industrial - São Paulo e Rio de Janeiro - e a fronteira agrícola - Paraná, Centro-Oeste e a região Norte; 2) trajetórias secundárias entre estados vizinhos articuladas ou não às dominantes. São notáveis os fluxos de São Paulo e dos estados do Sul em direção ao Paraná e ao Centro-Oeste e do Espírito Santo em direção ao Rio de Janeiro; 3) prevalência das migrações campo-cidade em todos os estados; 4) grande peso das migrações de longa distância; e 5) forte tendência de concentração populacional nas cidades com mais de 500 mil de habitantes e nas regiões metropolitanas.

As condições estruturais que deram suporte às trajetórias migratórias dominantes no período 1940-1980 transformaram-se: entre tais condições, vale o registro da desconcentração relativa das atividades econômicas iniciada na década de 1970. Verificam-se, ao longo dos anos 80 e 90, mudanças significativas no processo de distribuição espacial da população brasileira:

1. decremento na tendência de concentração populacional nas grandes capitais e regiões metropolitanas brasileiras, "metropolização", e aumento da taxa de crescimento dos municípios periféricos integrantes das regiões metropolitanas, "periferização";

2. contração no volume da migração rural-urbana;

3. incremento das migrações de curta distância e intrarregionais;

4. redução dos fluxos migratórios de longa distância, em particular os que se dirigiam às fronteiras agrícolas ;

5. declínio da capacidade de Minas e do Nordeste de gerar excedentes demográficos;

6. mantiveram-se como áreas de absorção dos fluxos de longa distância os estados de São Paulo, Rio de Janeiro, Goiás e Distrito Federal ${ }^{10}$;

7. aumento, sem precedentes, da migração de retorno em, praticamente, todos os estados brasileiros: “... de um volume estimado em cerca de 1,2 milhão na década de 70 , as pessoas que retornaram para seus estados de nascimento somaram quase 2,7 milhões na década seguinte"11. Fenômeno esse que se manifestou com maior intensidade nos estados do Nordeste, em Minas Gerais e no Paraná;

9 SALES, BAENINGER, op. cit.

10 Ibidem.

${ }^{11}$ CUNHA, José Marcos Pinto da; BAENINGER, Rosana. A migração nos estados brasileiros no período recente: principais tendências e mudanças, p. 53. 
8. “... surgimento e consolidação de polos de absorção migratória no âmbito inter-regional e intrarregional, com a maior parte dos estados tornando-se 'ganhadores' de população - mesmo que esses ganhos estejam circunscritos a contextos regionais específicos..." ${ }^{\prime 12}$.

É no corpo dessas transformações migratórias ocorridas na década de 1980 que se inscreve o renascimento do Brasil para a migração estrangeira. À acentuada redução das trocas migratórias internacionais que o Brasil assistiu no período 1940/1980, sobrevém, em meados dos anos 1980, nova etapa de mobilidade espacial de sua população. Em sintonia com a estrutura dos sistemas migratórios internacionais que se consolidaram no decorrer do último quartel do século XX e a crise da economia brasileira cujos sinais tornaram-se evidentes desde o final dos anos 1970: i) inflação acentuada e em ascensão; ii) elevado endividamento externo; iii) orçamento do governo federal onerado por subsídios compensatórios crescentes e pelo déficit de caixa; iv) exacerbada concentração econômica e de renda; e v) acentuado desequilíbrio do balanço de pagamentos ${ }^{13}$-, ganhou densidade a emigração internacional de brasileiros. Em 2002, o Departamento de Assistência Consular do Ministério das Relações Exteriores estimava em 1.964.498 o total de brasileiros residentes no exterior; total esse que, no ano de 2007, correspondia a 3.044.762 - elevação de 55\%. De acordo com a mesma fonte, a distribuição espacial desses emigrantes assumia, em 2007, a seguinte configuração: a América do Norte abrigava 1.278.650 brasileiros, a Europa, 766.629, a América do Sul, 611.708, a Ásia, 318.285, o Oriente Médio, 30.306, a Oceania, 17.250, a África, 15.323 e a América Central, 6.611 ${ }^{14}$.

Se até os anos 1990 certo vigor acompanha essas saídas de nacionais do Brasil para o estrangeiro, o que se verifica, em especial na segunda metade da década de 2000, é um incremento dos fluxos internacionais de entrada. Ao confrontar os dados dos censos demográficos de 2000 e de 2010, vem à luz o aumento de aproximadamente $87 \%$ do número de imigrantes internacionais em território brasileiro: no quinquênio 1995/2000, o Brasil recebeu 43.644 imigrantes e, no quinquênio 2005/2010, 268.295 ${ }^{15}$.

O foco sobre a recorrência espacial dos imigrantes, aqui denominada genericamente de mobilidade espacial interna, pode oferecer uma perspectiva epistemológica mais abrangente sobre a (re)organização espacial e (re)estruturação do território e indícios importantes sobre a dinâmica demográfica e econômica

12 BAENINGER, Rosana. Rotatividade migratória: um novo olhar para as migrações internas no Brasil, p. 81.

${ }^{13}$ BRUM, Argemiro F. Desenvolvimento econômico brasileiro; PEREIRA, Luiz Carlos Bresser. Desenvolvimento e crise no Brasil: 1930 - 1983.

${ }^{14}$ MINISTÉRIO DAS RELAÇÕES EXTERIORES (MRE). Brasileros no mundo.

${ }^{15}$ OlIVEIRA, Antônio Tadeu de. Um Panorama da Migração Internacional a partir do Censo Demográfico de 2010. 
no âmbito regional. Daí que o objetivo principal deste trabalho consiste tanto em evidenciar as recentes mudanças na composição das nacionalidades da população estrangeira residente no Brasil quanto em trazer à luz as diferenças no tocante à mobilidade espacial interna ao território brasileiro dessa mesma população. Com esse propósito, foram utilizadas as bases amostrais dos censos demográficos brasileiros de 1991, 2000 e 2010, o que permitiu identificar os imigrantes estrangeiros pela variável "nacionalidade" (também foram incluídos nesse grupo de migrantes, além dos que se declararam estrangeiros, os que se naturalizaram como brasileiros). A análise da migração da década incidiu sobre a seleção de estrangeiros que fixaram residência no Brasil no recorte temporal de 10 anos, contados de acordo como ano de referência de cada censo. A mobilidade espacial interna foi avaliada com base nos fluxos migratórios intermunicipais, definidos pela utilização combinada das variáveis que compõem a chamada migração de "data fixa" e "de última etapa", associada ao município de residência no período de referência de cada censo. Com isso, foi possível identificar os estrangeiros que, durante os períodos intercensitários, declaram residir em dois ou três municípios diferentes no Brasil, bem como o próprio movimento internacional (estrangeiros que fixaram residência no país há menos de 10 anos). Nessa etapa, os fluxos migratórios foram extraídos apenas das bases de 1991 e 2010, tendo em vista a retirada da variável que identifica o último município de residência do Censo de 2000.

\section{Migração estrangeira no Brasil: novos padrões na (re)distribuição da imigração internacional?}

Quando se têm em conta os dados referentes ao último levantamento censitário brasileiro, realizado em 2010, verifica-se (Tabela 1), quanto à migração acumulada, uma queda de 22,8\%: naturalizados e estrangeiros que, em 1991, somavam 767.781correspondiam, em 2010, a 592.570.

A Tabela 1 deixa ver ainda o crescimento relativo da população de estrangeiros naturalizados que representavam, em 2010, 27,2\% do total de não brasileiros residentes no território nacional: em 1991, essa proporção era de $21 \%$. Apesar da queda de 22,8\% no estoque acumulado de imigrantes internacionais entre 1991-2010 no Brasil, a imigração da década, obtida com base no ano de fixação de residência do imigrante internacional no país, experimentou acentuado crescimento: o total de 68.549 estrangeiros que, entre 1982 a 1991, fixaram residência no país sofreu, entre 2001 e 2010, uma elevação de quase duas vezes e meia - 164.420 imigrantes. Ao passo que a participação relativa dos imigrantes internacionais dos anos 80 era de quase $10 \%$ do estoque acumulado de imigrantes de 1991, a participação dos imigrantes correspondentes ao período 2001-2010 foi pouco menos de $28 \%$ do total de estrangeiros que residiam no Brasil em 2010 (Figura 1). 
Tabela 1: Distribuição absoluta e percentual dos imigrantes internacionais acumulados (life time) e dos imigrantes internacionais da década, estrangeiros ou naturalizados, residentes no Brasil em 1991, 2000 e 2010.

\begin{tabular}{|c|c|c|c|c|c|c|}
\hline \multirow[t]{2}{*}{ Situação } & \multicolumn{2}{|c|}{1991} & \multicolumn{2}{|c|}{2000} & \multicolumn{2}{|c|}{2010} \\
\hline & Abs & $\%$ & Abs & $\%$ & Abs & $\%$ \\
\hline $\begin{array}{l}\text { Imigração } \\
\text { acumulada }\end{array}$ & & & & & & \\
\hline Naturalizados & 161.152 & 20,99 & 173.763 & 25,41 & 161.250 & 27,21 \\
\hline Estrangeiros & 606.629 & 79,01 & 510.067 & 74,59 & 431.319 & 72,79 \\
\hline Total & 767.781 & 100 & 683.830 & 100 & 592.569 & 100 \\
\hline $\begin{array}{l}\text { Imigração } \\
\text { da década }\end{array}$ & & & & & & \\
\hline Naturalizados & 8.095 & 11,81 & 18.377 & 18,99 & 36.499 & 22,20 \\
\hline Estrangeiros & 60.454 & 88,19 & 78.375 & 81,01 & 127.921 & 77,80 \\
\hline Total & 68.549 & 100 & 96.752 & 100 & 164.420 & 100 \\
\hline
\end{tabular}

Fonte: Censos Demográficos de 1991, 2000 e 2010 (dados da amostra).

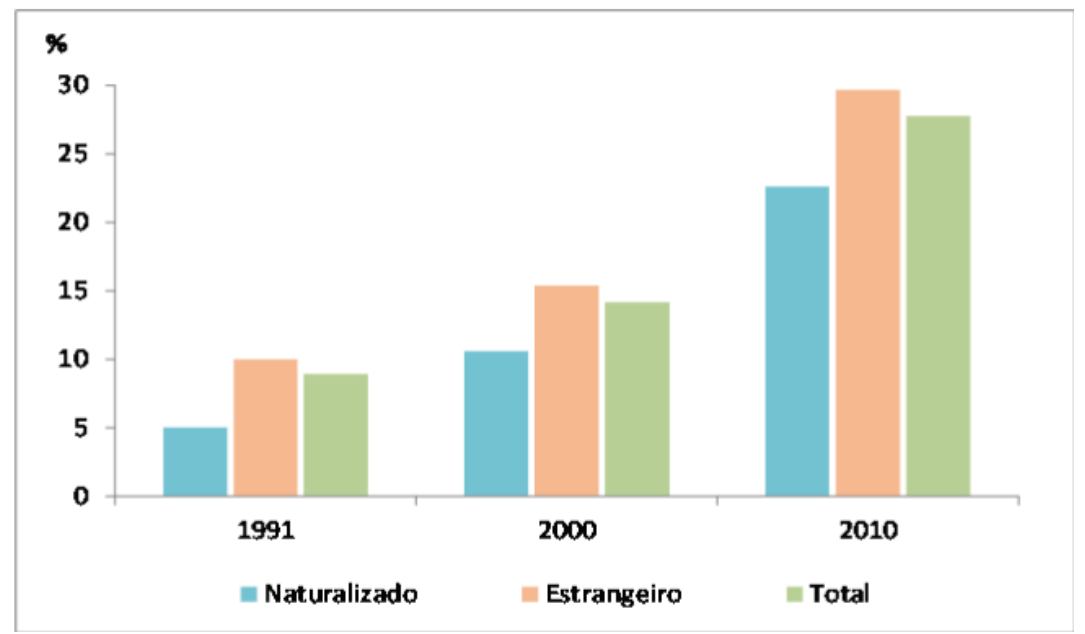

Fonte: Censos Demográficos de 1991, 2000 e 2010 (dados da amostra).

Figura 1: Participação da migração da década, estrangeiros ou naturalizados, no total de imigrantes acumulados residentes no Brasil em 1991, 2000 e 2010 
A distribuição desses imigrantes internacionais de acordo com o país de origem põe em evidência diferenças outras dignas de nota. Se forem considerados apenas os estrangeiros residentes no Brasil (Tabela 2), sem fazer caso da fixação do tempo de residência (imigração acumulada), verifica-se a predominância de portugueses, ainda que o número deles seja decrescente nas três últimas décadas. Os portugueses correspondiam a $23,3 \%$ do total de estrangeiros residentes no país em 2010; em 1991, essa proporção era de 34,3\%. Além dos japoneses, que, em 2010, respondiam por $8,28 \%$ da migração acumulada no Brasil, vale o registro da contribuição da imigração dos nacionais da Itália, da Espanha e da Alemanha - 6,27\%, 5,19\% e 2,74\%, respectivamente.

Tabela 2: Número e percentual de imigrantes estrangeiros (imigração acumulada) residentes no Brasil em 1991, 2000 e 2010

\begin{tabular}{|l|r|r|r|r|r|r|}
\hline \multirow{2}{*}{ Nacionalidades } & \multicolumn{2}{|c|}{1991} & \multicolumn{2}{|c|}{2000} & \multicolumn{2}{|c|}{2010} \\
\cline { 2 - 7 } & $\mathrm{N}^{\circ}$ & $\%$ & $\mathrm{~N}^{\circ}$ & $\%$ & $\mathrm{~N}^{\circ}$ & $\%$ \\
\hline Portugal & 263.611 & 34,33 & 213.203 & 31,18 & 137.972 & 23,28 \\
\hline Japão & 85.571 & 11,15 & 70.932 & 10,37 & 49.059 & 8,28 \\
\hline Paraguai & 19.018 & 2,48 & 28.822 & 4,21 & 39.251 & 6,62 \\
\hline Bolívia & 15.691 & 2,04 & 20.388 & 2,98 & 38.816 & 6,55 \\
\hline Itália & 66.294 & 8,63 & 55.032 & 8,05 & 37.165 & 6,27 \\
\hline Espanha & 57.887 & 7,54 & 43.604 & 6,38 & 30.736 & 5,19 \\
\hline Argentina & 25.468 & 3,32 & 27.531 & 4,03 & 29.067 & 4,91 \\
\hline Uruguai & 22.144 & 2,88 & 24.740 & 3,62 & 24.048 & 4,06 \\
\hline Estados Unidos & 11.360 & 1,48 & 13.948 & 2,04 & 23.513 & 3,97 \\
\hline China & 8.322 & 1,08 & 10.301 & 1,51 & 19.397 & 3,27 \\
\hline Alemanha & 24.329 & 3,17 & 19.556 & 2,86 & 16.241 & 2,74 \\
\hline Chile & 20.436 & 2,66 & 17.131 & 2,51 & 15.432 & 2,60 \\
\hline Peru & 5.833 & 0,76 & 10.814 & 1,58 & 15.020 & 2,53 \\
\hline Líbano & 17.187 & 2,24 & 16.090 & 2,35 & 12.336 & 2,08 \\
\hline Demais nacionalidades & 124.630 & 16,23 & 111.738 & 16,34 & 104.516 & 17,64 \\
\hline Total & 767.781 & 100,00 & 683.830 & 100,00 & 592.570 & 100,00 \\
\hline
\end{tabular}

Fonte: Censos Demográficos de 1991, 2000 e 2010 (dados da amostra).

Obs.: (1) Foram considerados estrangeiros aqueles que não nasceram no Brasil, nacionalizados ou não; (2) Foram discriminadas as nacionalidades com mais de 10 mil imigrantes no Censo de 2010.

Se a participação dos imigrantes latino-americanos na migração acumulada do Brasil em 1991, 2000 e 2010 não foi tão expressiva, não é o que se observa no caso da migração da década. A Tabela 3 dá a conhecer a prevalência dos estrangeiros oriundos de países da América Latina, em especial, dos paraguaios e dos bolivianos cuja contribuição era, respectivamente, de 13,46\% e de 12,14\% dos estrangeiros residentes no Brasil em 2010: até mesmo em 1991, os percentuais já eram consideráveis - 8,74\% e 10,06\%, nessa ordem. Com percentuais correspondentes 
a 9,33\% e 6,44\%, a participação de estadunidenses e de argentinos também ganha relevo em 2010. Portugueses e japoneses, que, no recorte temporal 2001-2010, fixaram residência no Brasil, totalizavam pouco mais de $10 \%$.

Tabela 3: Número e percentual de imigrantes da década, de nacionalidade estrangeira, residentes no Brasil em 1991, 2000 e 2010

\begin{tabular}{|c|c|c|c|c|c|c|}
\hline \multirow{2}{*}{ Nacionalidades } & \multicolumn{2}{|c|}{1991} & \multicolumn{2}{|c|}{2000} & \multicolumn{2}{|c|}{2010} \\
\hline & $\mathrm{N}^{\circ}$ & $\%$ & $\mathrm{~N}^{\circ}$ & $\%$ & $\mathrm{~N}^{\circ}$ & $\%$ \\
\hline Bolívia & 5.994 & 8,74 & 6.967 & 7,20 & 22.132 & 13,46 \\
\hline Paraguai & 6.897 & 10,06 & 11.156 & 11,53 & 19.953 & 12,14 \\
\hline Estados Unidos & 4.263 & 6,22 & 7.502 & 7,75 & 15.343 & 9,33 \\
\hline Argentina & 6.389 & 9,32 & 8.546 & 8,83 & 10.597 & 6,44 \\
\hline Portugal & 4.027 & 5,87 & 3.978 & 4,11 & 9.091 & 5,53 \\
\hline Japão & 2.030 & 2,96 & 4.712 & 4,87 & 7.823 & 4,76 \\
\hline Peru & 2.051 & 2,99 & 4.501 & 4,65 & 7.111 & 4,33 \\
\hline Uruguai & 6.098 & 8,90 & 5.667 & 5,86 & 7.044 & 4,28 \\
\hline China & 1.758 & 2,56 & 3.080 & 3,18 & 5.922 & 3,60 \\
\hline Itália & 1.768 & 2,58 & 3.782 & 3,91 & 5.592 & 3,40 \\
\hline França & 1.660 & 2,42 & 3.029 & 3,13 & 4.567 & 2,78 \\
\hline Espanha & 1.114 & 1,62 & 1.948 & 2,01 & 4.544 & 2,76 \\
\hline Colômbia & 822 & 1,20 & 2.059 & 2,13 & 4.371 & 2,66 \\
\hline Alemanha & 1.965 & 2,87 & 3.231 & 3,34 & 4.138 & 2,52 \\
\hline Grã-Bretanha & 1.062 & 1,55 & 1.813 & 1,87 & 2.771 & 1,69 \\
\hline Chile & 5.124 & 7,47 & 1.901 & 1,97 & 2.569 & 1,56 \\
\hline Coréias & 3.287 & 4,80 & 1.622 & 1,68 & 2.525 & 1,54 \\
\hline Angola & 818 & 1,19 & 2.067 & 2,14 & 2.388 & 1,45 \\
\hline México & 286 & 0,42 & 631 & 0,65 & 1.868 & 1,14 \\
\hline Líbano & 1.364 & 1,99 & 2.479 & 2,56 & 1.671 & 1,02 \\
\hline Venezuela & 564 & 0,82 & 1.183 & 1,22 & 1.594 & 0,97 \\
\hline Suíça & 661 & 0,96 & 1.038 & 1,07 & 1.106 & 0,67 \\
\hline Holanda & 447 & 0,65 & 767 & 0,79 & 1.091 & 0,66 \\
\hline Cuba & 74 & 0,11 & 892 & 0,92 & 1.078 & 0,66 \\
\hline Equador & 257 & 0,37 & 545 & 0,56 & 1.057 & 0,64 \\
\hline Demais nacionalidades & 7.769 & 11,33 & 11.656 & 12,05 & 16.475 & 10,02 \\
\hline Total & 68.550 & 100,00 & 96.752 & 100,00 & 164.420 & 100,00 \\
\hline
\end{tabular}

Fonte: Censos Demográficos de 1991, 2000 e 2010 (dados da amostra).

Obs.: (1) Foram considerados estrangeiros aqueles que não nasceram no Brasil, nacionalizados ou não. (2)

Foram discriminadas as nacionalidades com mais de mil imigrantes no Censo de 2010.

\section{Mobilidade espacial interna: algumas evidências recentes}

Os dados constantes na Tabela 4 levam ao conhecimento de que a mobilidade espacial interna, isto é, os fluxos migratórios intermunicipais dos estrangeiros que passaram a residir no Brasil entre 1982 e 1991 e entre 2001 e 2010 não é desprezível. Cerca de 1/4 desses estrangeiros contados no censo de 1991 e no de 2010, que somavam quase 40 mil neste último censo, responderam por pelo menos um movimento migratório intermunicipal no 
Brasil, seja de acordo com informação advinda do quesito referente à última etapa, seja pela oriunda do quesito de data fixa. Nota-se um crescimento do número de imigrantes internacionais de todas as nacionalidades, exceto o de uruguaios, que mudaram de residência no do território brasileiro. O caso mais notório é o dos bolivianos: em 1991, apenas 705 deles mudaram de município no Brasil, já, na década seguinte, esse número era superior a 6 mil.

Tabela 4: Número e percentual de imigrantes da década residentes no Brasil em 1991, 2000 e 2010 que realizaram ou não migração interna (migração intermunicipal de data fixa ou de última etapa)

\begin{tabular}{|l|c|c|c|c|c|c|c|c|}
\hline \multirow{2}{*}{ Nacionalidade } & \multicolumn{4}{|c|}{1991} & \multicolumn{4}{c|}{2010} \\
\cline { 2 - 9 } & Não Migrantes & Migrantes & Não Migrantes & \multicolumn{2}{c|}{ Migrantes } \\
\cline { 2 - 9 } & $\mathbf{N}^{\circ}$ & $\%$ & $\mathbf{N}^{\circ}$ & $\%$ & $\mathbf{N}^{\circ}$ & $\%$ & $\mathbf{N}^{\circ}$ & $\%$ \\
\hline Bolívia & 5.289 & 88,23 & 705 & 11,77 & 16.014 & 72,36 & 6.118 & 27,64 \\
\hline Paraguai & 4.394 & 63,70 & 2.503 & 36,30 & 15.231 & 76,33 & 4.722 & 23,67 \\
\hline Estados Unidos & 3.578 & 83,93 & 685 & 16,07 & 11.896 & 77,53 & 3.447 & 22,47 \\
\hline Argentina & 5.041 & 78,89 & 1.348 & 21,11 & 8.105 & 76,49 & 2.492 & 23,51 \\
\hline Portugal & 3.392 & 84,23 & 635 & 15,77 & 7.321 & 80,53 & 1.770 & 19,47 \\
\hline Japão & 1.732 & 85,35 & 297 & 14,65 & 5.931 & 75,81 & 1.892 & 24,19 \\
\hline Peru & 1.625 & 79,20 & 427 & 20,80 & 4.976 & 69,97 & 4.135 & 30,03 \\
\hline Uruguai & 2.806 & 46,01 & 3.292 & 53,99 & 5.492 & 77.98 & 1.551 & 22,02 \\
\hline China & 1.573 & 89,51 & 184 & 10,49 & 4.480 & 75,65 & 1.442 & 24,35 \\
\hline Itália & 1.550 & 87,70 & 217 & 12,30 & 4.028 & 72,03 & 1.564 & 27,97 \\
\hline
\end{tabular}

Fonte: Censos Demográficos de 1991, 2000 e 2010 (dados da amostra).

Obs.: (1) Foram considerados estrangeiros aqueles que não nasceram no Brasil, nacionalizados ou não. (2)

Foram discriminadas as nacionalidades aquelas com mais de mil imigrantes no Censo de 2010 que também migraram internamente.

A configuração territorial assumida pelos deslocamentos internos dos estrangeiros de certas nacionalidades, expressa pelas Figuras 2, 3 e 4, sugerem algumas peculiaridades geográficas. Os paraguaios, que fixaram residência no Brasil entre 1991/1982 e declararam residir em pelo menos dois municípios brasileiros diferentes na mesma década, concentraram-se nas áreas de fronteira, sobretudo nas circunvizinhanças de Foz do Iguaçu, bem como nas áreas de expansão/consolidação agrícola brasileira - Mato Grosso e Mato Grosso do Sul/ Oeste do Paraná. A capital paulista, incluindo os municípios que compõem sua periferia metropolitana, também aglutinou imigrantes internacionais do Paraguai. Além do estado de Rondônia, a maior presença de bolivianos ocorreu no Rio de Janeiro e em São Paulo, onde a concentração foi mais acentuada. Os estadunidenses, por sua vez, localizaram-se predominantemente nos grandes centros urbanos do centro-sul brasileiro, com destaque adicional para as áreas circunvizinhas de Brasília e de Governador Valadares/MG. 
Figura 2: Imigrantes naturais do Paraguai, residentes no Brasil em 1991 e 2010, que realizaram migração intermunicipal no território nacional
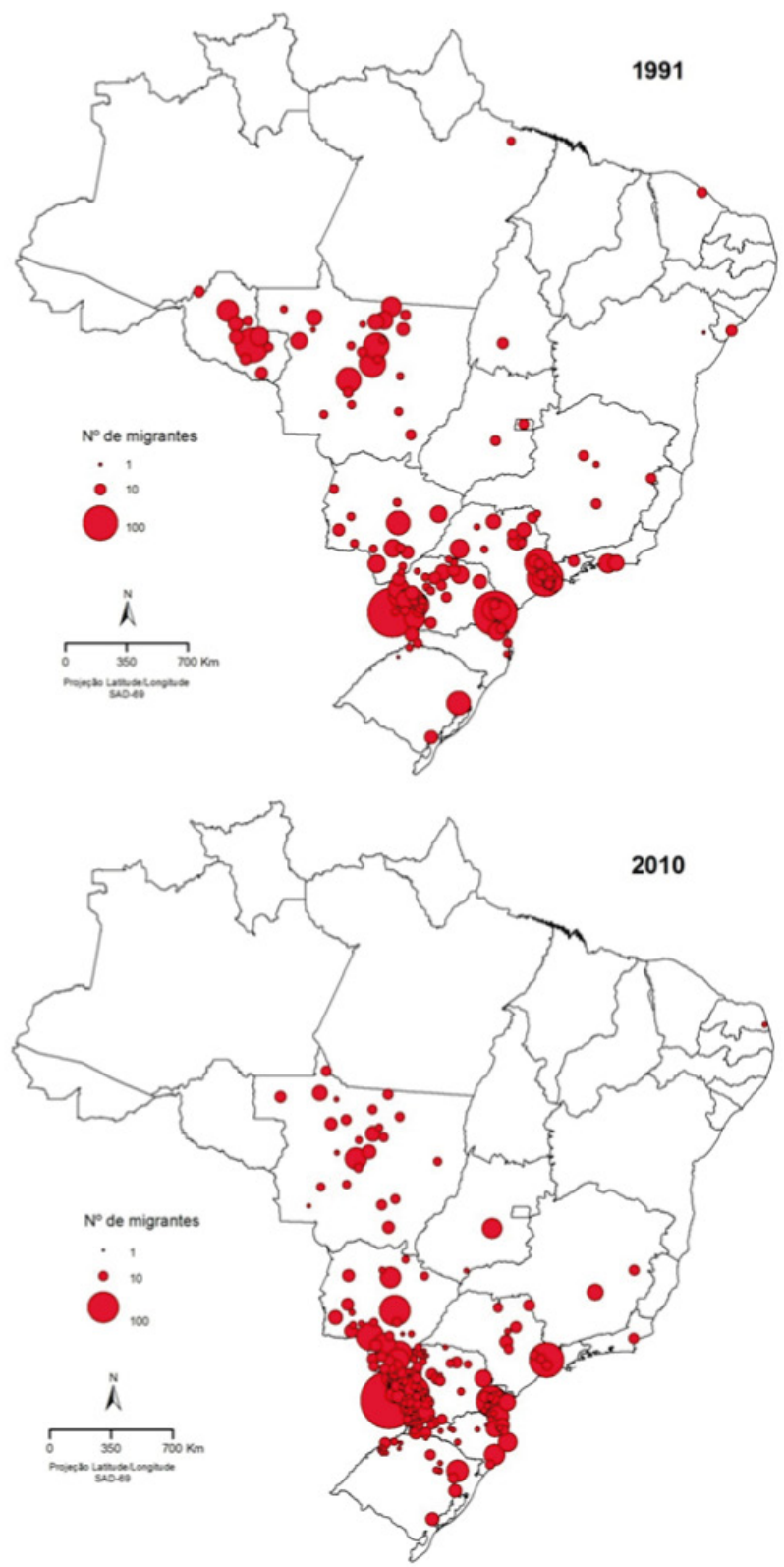

Fonte: IBGE. Censos Demográficos de 1991 e 2000 (dados da amostra) 
Figura 3: Imigrantes naturais da Bolívia, residentes no Brasil em 1991 e 2010, que realizaram migração intermunicipal no território nacional
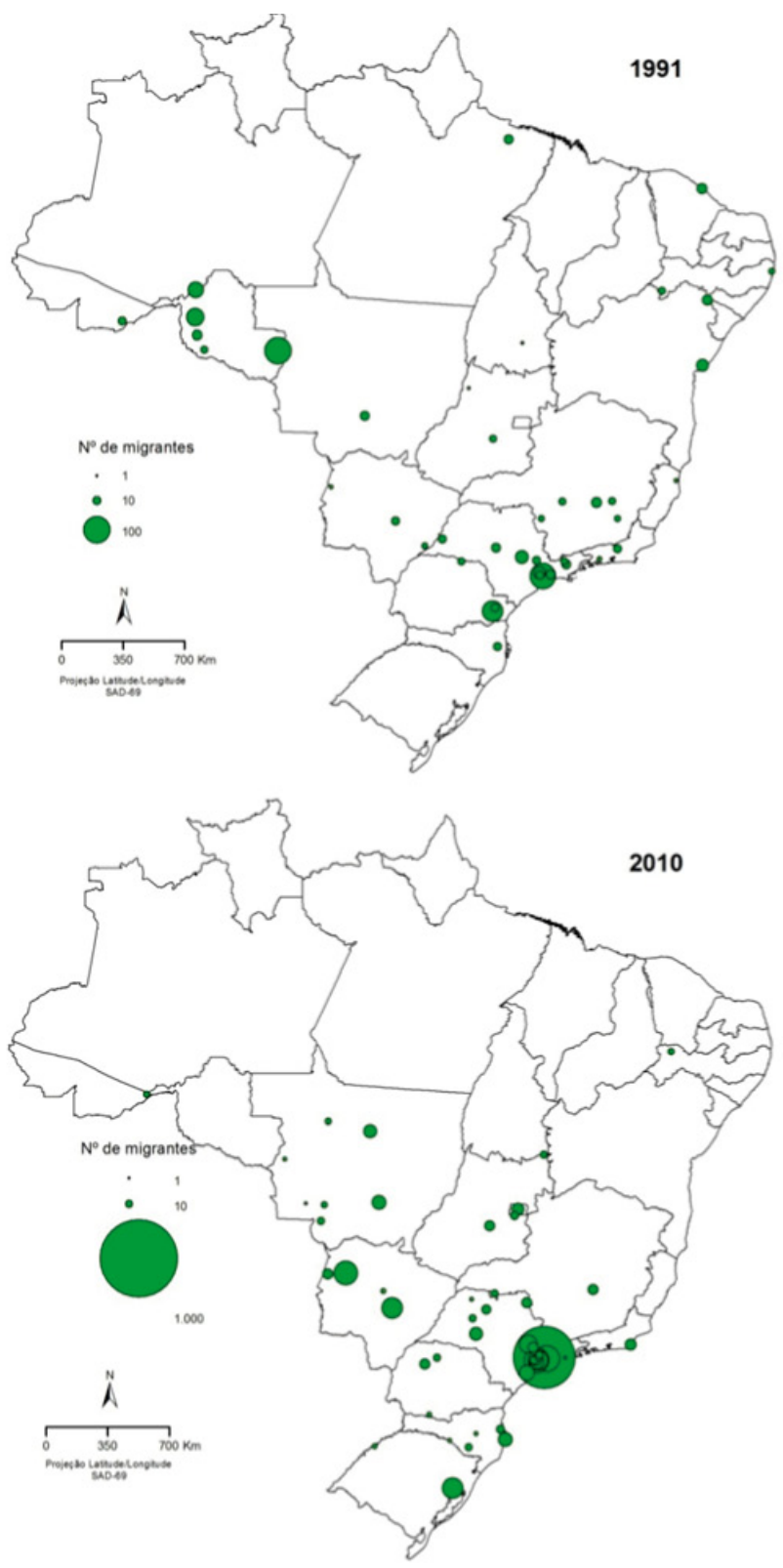

Fonte: IBGE. Censos Demográficos de 1991 e 2000 (dados da amostra) 
Figura 4: Imigrantes naturais dos Estados Unidos, residentes no Brasil em 1991 e 2010, que realizaram migração intermunicipal no território nacional
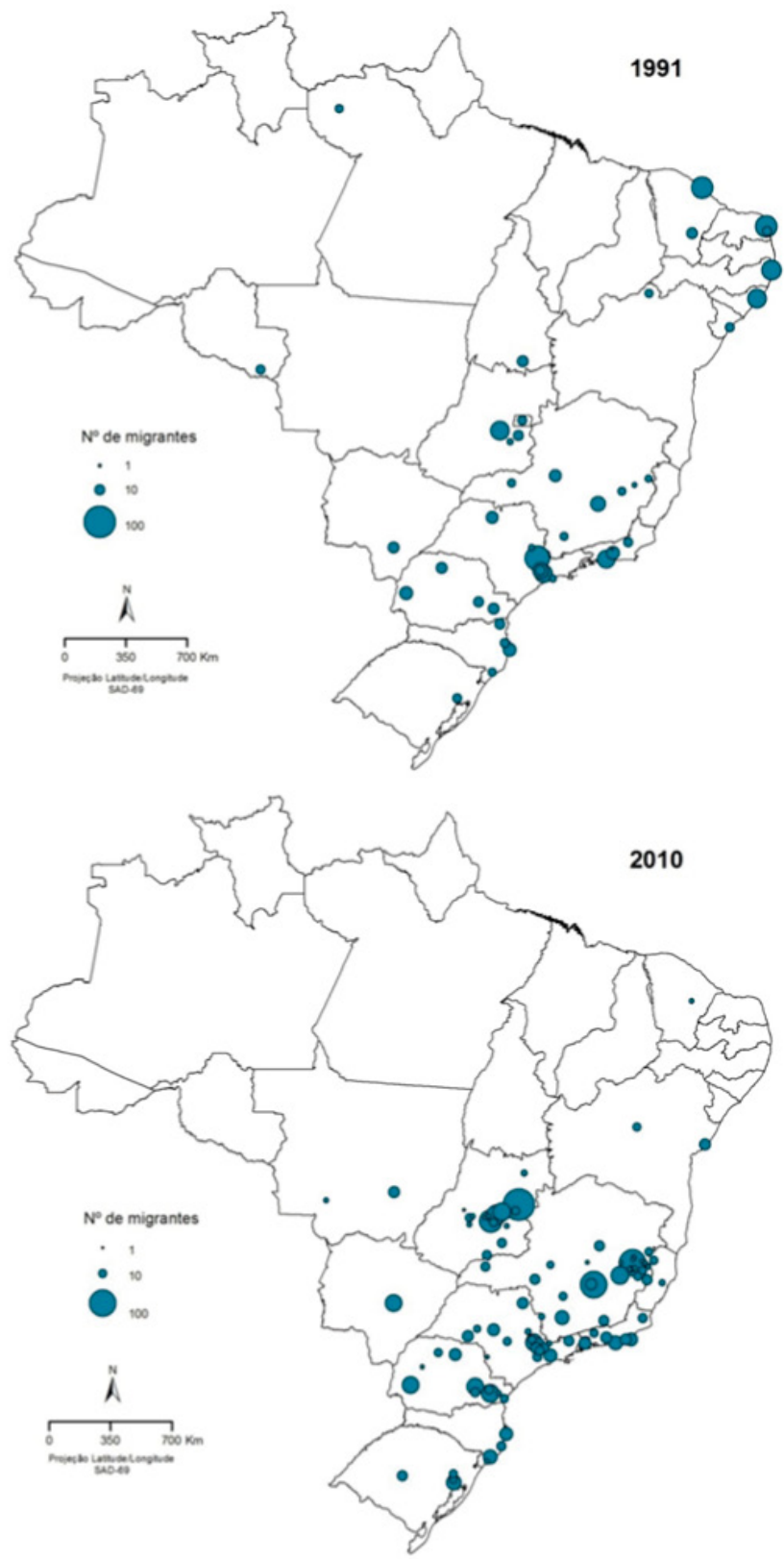

Fonte: IBGE. Censos Demográficos de 1991 e 2000 (dados da amostra) 


\section{Conclusões}

Antigas e novas territorialidades parecem se afirmar no Brasil meridional em razão dos fluxos populacionais que contribuíram para nova etapa de estruturação das relações entre o Brasil e os países vizinhos. No cenário das trocas populacionais na América Latina em período recente, os dados dão a conhecer que, apesar do crescimento relativo da população de estrangeiros naturalizados em território brasileiro, o Brasil conviveu com uma tendência declinante da entrada de imigrantes internacionais. E mais, mesmo considerando apenas os migrantes da década, uma significativa parcela desses imigrantes estrangeiros protagonizou pelo menos um movimento migratório ao longo dessa curta estada no Brasil, reflexo direto da ampliação das relações do Brasil com os países vizinhos.

Ao que parece, a dinâmica migratória intrarregional constitui reflexo de novos arranjos políticos e econômicos na América Latina, bem como de novas alternativas ensejadas pelos desafios decorrentes da chamada globalização econômica em curso em diversos países do continente americano. Medidas e ações governamentais que interferem diretamente nas variações tarifárias e cambiais, assim como as políticas agrícolas, implementadas nos diversos países da região, desencadeiam, direta ou indiretamente, os movimentos populacionais, sobretudo os que ocorrem nas zonas de fronteira. Esses fluxos espaciais da população, como sugerem Patarra e Baeninger ${ }^{16}$, envolvem não apenas mudança de residência; aglutinam também outros tipos mobilidades, como os movimentos sazonais ou circulares, associados a ciclos econômicos e às atividades agrícolas, à construção de grandes obras e ao comércio.

Os emigrantes do passado recente alimentavam movimentos de retorno que ainda integram os fluxos atuais de imigração. O migrante sul-americano que passa a residir no Brasil concentra-se, como antes, nas zonas de fronteira, sobretudo na porção brasileira da bacia hidrográfica Paraguai/Paraná, ainda que outras regiões do País, como as áreas metropolitanas, recebam também relevante porção desses migrantes. Essa concentração é resultado, em boa medida, da centralidade regional exercida pelo núcleo e as circunvizinhanças de Foz do Iguaçu e da atração da agroindústria localizada no Sul e no Centro-Oeste brasileiro, responsáveis pela crescente recepção de imigrantes procedentes do Paraguai. Em menor volume, é também notável a presença de imigrantes na região do litoral sul, sobretudo na Região Metropolitana de Curitiba e de Porto Alegre, bem como no Sul de Mato Grosso do Sul e nos estados de Mato Grosso e de Rondônia ${ }^{17}$.

16 PATARRA, Neide Lopes; BAENINGER, Rosana. Migrações internacionais, globalização e blocos de integração econômica - Brasil no Mercosul.

17 MATOS, Ralfo et alii. Conexões geográficas e movimentos migratórios internacionais no Brasil Meridional. 
Por fim, convém salientar que os dados mais recentes sobre os fluxos migratórios internacionais dão margem ao entendimento de que o Brasil ampliou as oportunidades de inserção da força de trabalho no mercado laboral e de abriu possibilidades de investimentos empresariais, o que favoreceu a imigração e, em certa medida, inibiu a emigração.

\section{Referências bibliográficas}

BAENINGER, Rosana. Rotatividade migratória: um novo olhar para as migrações internas no Brasil. REMHU, Rev. Interdisciplinar da Mobilidade Humana, Brasília, v. 20, n. 39, jul./dez. 2012, p. 77-100.

BAENINGER, Rosana. Fases e faces da migração em São Paulo. Campinas: Núcleo de Estudos de População/UNICAMP, 2012.

BRUM, Argemiro F. Desenvolvimento econômico brasileiro. Petrópolis: Vozes, 1995. CUNHA, José Marcos Pinto da; BAENINGER, Rosana. A migração nos estados brasileiros no período recente: principais tendências e mudanças. In HOGAN, Daniel Joseph et alii (orgs.). Migração e ambiente em São Paulo: aspectos relevantes da dinâmica recente. Campinas: Núcleo de Estudos de População/UNICAMP, 2000, p. 17-57.

FURTADO, Celso. Formação econômica do Brasil. São Paulo: Nacional, 1998.

LEVY, Maria Stella F. O papel da migração internacional na evolução da população brasileira (1872 a 1972). Revista Saúde Pública, S. Paulo, n. 8 (suplemento), 1974, p. 49-90.

MARTINE, George. A evolução espacial da população brasileira. In AFFONSO, Rui de B. A.; SILVA, Pedro Luiz B. (orgs.). Desigualdades regionais e desenvolvimento. São Paulo: FUNDAP: Editora da UNESP, 1995, p. 61-91.

MARTINE, George. Adaptação dos migrantes ou sobrevivência dos mais fortes. In MOURA, Hélio de (coord.). Migrações internas: textos escolhidos. Fortaleza: BNB/ ETENE, t. 2, 1980, p. 949-974.

MARTINE, George. As migrações de origem rural no Brasil: uma perspectiva histórica. In NADALIN, Sérgio O. et alii (org.). História e População. São Paulo: ABEP/IUSSP/ CELADE, 1990, p. 16-26.

MARTINE, George. Estado, economia e mobilidade geográfica: retrospectiva e perspectivas para o fim do século. Revista Brasileira de Estudos de População, Campinas, v. 11, n. 1, 1994, p. 41-60.

MATOS, Ralfo et alii. Conexões geográficas e movimentos migratórios internacionais no Brasil Meridional. I Congreso de la Asociación Latino-America de Población (ALAP), Caxambu, Setembro, 2004.

MINISTÉRIO DAS RELAÇÕES EXTERIORES (MRE). Brasileros no mundo. Brasilia: Departamento Consular e de Brasileiros no Exterior, 2008. Disponível em: <http:// www.abe.mre.gov.brmundo/america-do-sul/republica-federativa-do-brasil/ subsecretaria-geral-das-comunidades-brasileiras-no-exterior/avisos/newsitem 
view2?id=brasileiros-no-mundo $>$. Acesso em: 21.08.2009.

OLIVEIRA, Antônio Tadeu de. Um Panorama da Migração Internacional a partir do Censo Demográfico de 2010. REMHU, Revista Interdisciplinar da Mobilidade Humana, Brasília, v. 21, n. 40, jul./dez. 2013, p.195-210.

PATARRA, Neide Lopes; BAENINGER, Rosana. Migrações internacionais, globalização e blocos de integração econômica - Brasil no Mercosul. I Congreso de la Asociación Latino-America de Población (ALAP), Caxambu, Setembro, 2004.

PEREIRA, Luiz Carlos Bresser. Desenvolvimento e crise no Brasil: 1930 - 1983. São Paulo: Brasiliense, 1985.

SALES. Teresa; BAENINGER, Rosana. Migrações internas e internacionais no Brasil: panorama deste século. Travessia. Revista do Migrante, São Paulo, n. 36, jan/abril 2000, p. 33-44.

\section{Abstract}

Spatial mobility of foreign immigrants in Brazil - 1991/2010

International and internal migration plays an important role in the formation of Brazilian territory. In the middle of the twentieth century, new waves of migration caused the most recent changes in the social and spatial dynamics of Brazil. Alongside traditional destinations' such as Japan and the United States, new internal population movements within South America have gained importance, including flows from the Brazilian territory. In light of such migratory dynamics, the main purpose of this paper is the lifting of different nationalities of international immigrants resident in Brazil and the analysis of differences in internal spatial mobility of those immigrants.

Keywords: spatial mobility, international migration, internal migration.

Recebido para publicação em 09/02/2015.

Aceito para publicação em 22/04/2015. Received for publication on February, 09 ${ }^{\text {th }}, 2015$. Accepted for publication on April, 22 ${ }^{\text {th }}, 2015$. 